\title{
A Probabilistic Approach for Assessment of Future Drought in Bagmati River Basin, Nepal
}

\author{
Rajendra Man Shrestha ${ }^{1^{*}}$, Azaya Bikram Sthapit ${ }^{2}$ and Srijan Lal Shrestha ${ }^{3}$ \\ Submitted: 24 July 2018; Accepted: 19 August 2018
}

Published online: 26 September 2018

DOI: http://dx.doi.org/10.3126/njs.v2i0.21156

\begin{abstract}
Background: The Bagmati River is the rain-fed river in the basin of Nepal. The climate change in rainfall patterns may lead to drought or flashflood in this basin. Drought is a silent and pervasive hazard due to the deficit of water availability. It may have adverse impact on society leading to impact on environment, culture, political and other functions of the region.
\end{abstract}

Objective: This study aims to assess the future drought in the Bagmati River Basin, Nepal.

Materials and Methods: Providing Regional Climates for Impact Studies precipitation data was obtained from Department of Hydrology and Meteorology, Kathmandu. The Generalized Extreme Distribution was fitted to respective total precipitations in 3 time-scales using EasyFit software. Standardized Precipitation Index (SPI) method was used to derive SPI for winter drought, SPI for summer drought and SPI for long-term (annual) drought.

Results: The results of data analysis showed that winter moderate drought episodes may occur in years 2035, 2042, 2048, 2049, 2051 and 2053. Likewise, summer severe drought episode may occur in 2046. The year 2046 also indicated long-term extreme drought. Moreover, 2030, 2031, 2035, 3040 and 2053 may be long-term moderate drought episodes years in future.

Conclusion: There may be winter moderate drought, summer severe drought and a long-term extreme as well as moderate drought during the future period 2030-2060.

Keywords: Drought, ECHAM05-MRI with SRES A1B, general circulation models, rainfall, probability distribution, standardized precipitation index.

Address correspondence to the authors: Padma Kanya Multiple Campus, Kathmandu.

Email: rajendramanshrestha65@gmail.com ${ }^{1 *}$ (corresponding author email); Global College of Management, Kathmandu. Email: azaya.sthapit@gmail.com²; Central Department of Statistics, Tribhuvan University, Kirtipur, Kathmandu, Nepal. Email: srijan_shrestha@yahoo.com³

Copyright \& License @ Central Department of Statistics, TU, 201875 


\section{INTRODUCTION}

Extreme rainfalls and droughts are considered as extreme hydrological events all over the world. They may have adverse impact on society leading to impact on environment, culture, political and other functions of the region (Deka, Boraj, \& Kakty, 2009). Drought is a silent and pervasive hazard and happens due to the deficit of water availability (Shrestha et al., 2014). According to Obasi (1994), approximately 85 percent of natural disasters are all associated with the droughts, which are usually considered as one of the most complicated and least understood natural hazards. Among such hazards, it is experienced that drought starts slowly without warning, for example, it may occur as below-average rainfall within a normal part of rainfall (Sigdel \& Ikeda, 2010) or it may gradually turn into hazardous event and last for significantly longer period of time encapsulating large spatial parts (Shrestha et al., 2014). According to several research articles, happening of such devastating drought events in many parts of world including Asia have faced a significant decline in the agriculture production due to increased frequency and severity of drought (Sigdel \& Ikeda, 2010). Sigdel and Ikeda (2010) had also mentioned about the drought happening events in Nepal with some spatialvariation. Further, Shrestha et al. (2016) has investigated and found that the summer season of 2004, 2005, 2006 and 2009; and also winters of 2006, 2008 and 2009 were the worst widespread droughts in drought risk assessment in central Nepal.

Climate variables like high temperature, high wind and low relative humidity may pose as causative factors of drought in many parts of the world but among them rainfall is considered as the primary climate variable because it may control the formation and persistence of drought condition and hence further aggravate severity of the drought in the region (Sigdel \& Ikeda, 2010). Summer monsoon ( $80 \%$ of total precipitation) and winter are two main seasons associated with major crop productions in Nepal, e.g., rice and wheat. Precipitation is dominant water source for the production in Nepal and likewise in the region of the Bagmati River Basin. Hydroelectricity, drinking water and irrigation are some of the main factors that can make better livelihood of people in Nepal. Thus, small sign of happening of drought may lead to serious consequences on the national economy for the short or the long period (Sigdel \& Ikeda, 2010). The Bagmati River Basin has only rainfall as a water source for river and is also considered the most water stressed basin in Nepal. The basin is observed with a decline in water resources availability owing to natural and anthropogenic causes. Consequently, climate change in rainfall patterns may lead to drought or flashflood in this basin. Although there have been some studies on rainfall patterns over Nepal (Shrestha, 2000; Shrestha \& Aryal., 2010; Kafle, 2014; Wang, Yoon, Gilles, \& Cho, 2013; Shrestha et al., 2014; Sigdel, \& Ikeda, 2010; Nepal, 2016), the study concerning on drought is found limited, and more specifically for the region: the Bagmati River Basin, Nepal. At the same time, there have been no sufficient studies available for the drought assessment inconnection with future climate scenarios in Nepal. 
In the view of understanding the adverse consequences of drought in the region, it is necessary to monitor and assess the drought situation so that policy makers and planners and concerned government agencies could take required action timely to mitigate possible consequences by drought. Thus, this study aims to assess future drought using standard precipitation index in the Bagmati River Basin, Nepal.

\section{MATERIALS AND METHODS}

This section is described in several sub-sections as follows.

\section{Study area}

The Bagmati River Basin (Figure 1) is located within the middle mountain of Nepal. It extends from $26^{\circ} 45^{\prime} \mathrm{N}-27^{\circ} 49^{\prime} \mathrm{N}$ and $85^{\circ} 02^{\prime} \mathrm{E}-85^{\circ} 27^{\prime} \mathrm{E}$ and has a catchment area of $3,750 \mathrm{~km}^{2}$ in Nepal. The Bagmati River originates from the Shivapuri hills of the Mahabharata range in the Kathmandu Valley and drains out of Nepal across the India state-Bihar. It reaches the River Ganges after passing through the inner Mahabharata range and the plain of Terai. It is mentioned that the elevation of the Bagmati River Basin ranges from about less than $80 \mathrm{~m}$ in Terai, its southern part to $2900 \mathrm{~m}$ in the Mahabharata range, its northern part (Babel, Bhusal, Wahid, \& Aarwal, 2013). Its length is about 51 $\mathrm{km}$ in Nepal. Its main tributaries are Manohara, Bishnumati, Kulekhani, Kokhajor, Marin, Chandi, Jhanjh and Manusmara. The Kathmandu Valley comprises 15\% of the basin area in Nepal. Main sources of water in the Bagmati River Basin are rain and natural springs (Babel et al., 2013).

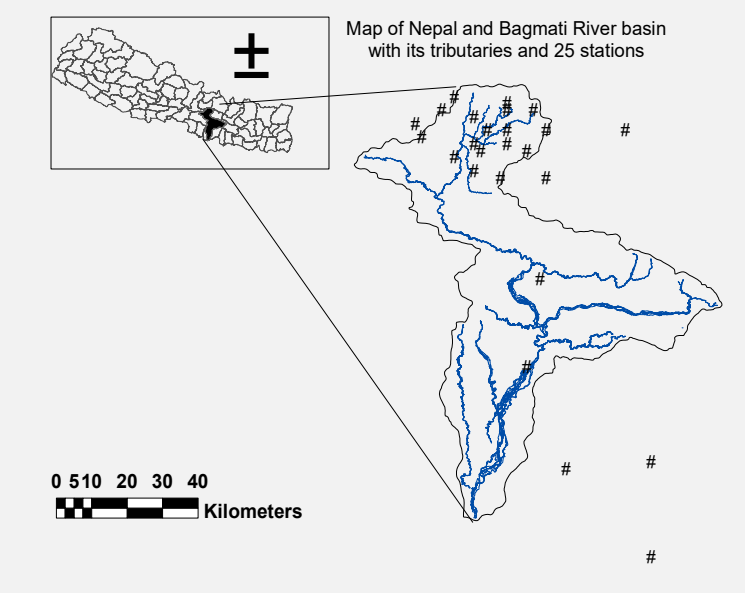

Fig. 1. Map of the Bagmati River Basin in Nepal with tributaries and 25 meteorological stations.

Data

This paper attempts to deal with what would be the future scenario of the rainfall patterns with reference to its extreme event like drought or precisely severity of drought under the influence of climate change. The monthly Providing Regional Climates for Impact Studies (PRECIS) data, data of Regional Climate Model (RCM) are obtained for $25 \mathrm{~km}$ horizontal resolution from the Department of

Copyright \& License @ Central Department of Statistics, TU, 201877 
Hydrology and Meteorology (DHM), Kathmandu. The PRECIS Model (RCM) is found to perform better to provide reasonable mean and variance values after bias correction. It provides the data by simulation from the GCM, ECHAM05-MPI with A1B scenario. A1B storyline and its family give a moderate scenario and describe a future world of a very rapid economic growth, global population that peaks in the mid- $21^{\text {st }}$ century and declines thereafter, and the rapid introduction of new and more efficient technologies (DHM, 2013). PRECIS RCM data of the monthly precipitation are extracted from the domain of Nepal $\left(79.0^{\circ} \mathrm{E}-90.0^{\circ} \mathrm{E} ; 25.0^{\circ} \mathrm{N}-32.0^{\circ} \mathrm{N}\right)$ to the domain of Bagmati River Basin domain $\left(84.92^{0}\right.$ E- $86.02^{0}$ E; $\left.26.4^{0} \mathrm{~N}-27.74^{0} \mathrm{~N}\right)$. The data belong to ECHAM05-MPI with SRES A1B. Thiessen polygon method was used to execute 19 areas (Table 1) by dividing whole Basin such that there are corresponding 19 time-series of the rainfall data for Baseline (1971-2000) and Future (2030-2060). By using weighted arithmetic mean, area weighted monthly rainfall time-series is generated as a single time-series to represent the rainfall pattern in aggregate of the basin.

Table 1. Area calculation based on PRECIS ECHAM5Q030A1B-Precipitation using Thiessen Polygon method in ArcMap

\begin{tabular}{cccccccccr}
\hline Object ID & ID & Input ID & Sn & Lat & Lon & Rain & Shape Length & Shape Area & \multicolumn{1}{c}{ Area } \\
\hline 1 & 0 & 17 & 23 & 26.86 & 85.58 & 13.38 & 0.05 & 0.00 & 1.22 \\
2 & 0 & 27 & 39 & 27.30 & 86.02 & 10.14 & 0.19 & 0.00 & 23.20 \\
3 & 0 & 19 & 25 & 27.30 & 85.58 & 8.60 & 0.88 & 0.05 & 530.73 \\
4 & 0 & 11 & 17 & 27.08 & 85.36 & 12.30 & 0.85 & 0.05 & 503.52 \\
5 & 0 & 10 & 16 & 26.86 & 85.36 & 13.95 & 0.75 & 0.03 & 321.66 \\
6 & 0 & 9 & 15 & 26.64 & 85.36 & 15.55 & 0.06 & 0.00 & 1.37 \\
7 & 0 & 4 & 10 & 27.08 & 85.14 & 13.53 & 0.10 & 0.00 & 2.48 \\
8 & 0 & 23 & 31 & 27.08 & 85.80 & 11.29 & 0.31 & 0.00 & 18.88 \\
9 & 0 & 18 & 24 & 27.08 & 85.58 & 11.81 & 0.85 & 0.01 & 152.71 \\
10 & 0 & 25 & 33 & 27.52 & 85.80 & 17.33 & 0.13 & 0.00 & 4.97 \\
11 & 0 & 24 & 32 & 27.30 & 85.80 & 9.29 & 0.80 & 0.04 & 428.90 \\
12 & 0 & 20 & 26 & 27.52 & 85.58 & 16.33 & 0.58 & 0.01 & 132.75 \\
13 & 0 & 13 & 19 & 27.52 & 85.36 & 15.74 & 0.93 & 0.04 & 443.76 \\
14 & 0 & 12 & 18 & 27.30 & 85.36 & 11.44 & 0.85 & 0.04 & 398.16 \\
15 & 0 & 6 & 12 & 27.52 & 85.14 & 18.12 & 0.78 & 0.02 & 202.99 \\
16 & 0 & 0 & 5 & 27.52 & 84.92 & 15.23 & 0.03 & 0.00 & 0.32 \\
17 & 0 & 14 & 20 & 27.74 & 85.36 & 13.25 & 0.78 & 0.04 & 414.56 \\
18 & 0 & 7 & 13 & 27.74 & 85.14 & 16.46 & 0.61 & 0.01 & 120.11 \\
19 & 0 & 21 & 27 & 27.74 & 85.58 & 13.60 & 0.37 & 0.00 & 53.16 \\
\hline ID = Identification; Lat $=$ Latitude; Lon & Longitude; & & Total Area & 3755.44
\end{tabular}




\section{Method}

Method is described as follows.

\section{Standardized precipitation index}

The Standardized Precipitation Index (SPI), designed by McKee, Doesken, and Kleist (1993), is widely used as a quantitative measure of drought for its forecasting, frequency analysis, spatiotemporal analysis and climate change impact studies (Mishra \& Singh. 2010). It is the simplest one among all indicators like Palmer Drought Severity Index and Standardized Precipitation Evapotranspiration Index as it requires only precipitation as input. It is generally determined for trimonthly, half yearly, yearly and 2-yearly (Edwards \& McKee, 1997). It can be defined for any timescale of interest and further is comparable in both time and space. Its additional advantage is that it is not affected by geographical and topographical differences (Lana, Serra, \& Burgueno, 2001). In this study, the SPI is calculated for 3-, 4-, and 12-month time scales. They belong to SPI-3, SPI-4 and SPI-12, respectively. SPI-3 is a measure of winter drought, SP-4, a measure of summer monsoon drought and SPI-12, a measure of long-term drought.

According to Guttman $(1998,1999)$, the first step in the calculation of the SPI is to fit a probability density function (pdf) which describes the long-term series of observations (here after $X$, is considered as a random variable). Then, the cumulative probability (cdf, denoted by $\mathrm{G}(x)$ ) of the observed precipitation amount $(X)$ is determined. Using the formula proposed by Abramowitz and Stegun (1965), the SPI was calculated. This study attempts to identify the most common distributions, which are usually recommended in the past SPI studies. They include Gamma, Lognormal, Logistic, Weibul and Generalized Extreme Value (GEV) distributions. Distributions are fitted by both L-Moments and Maximum likelihood estimation (MLE) wherever possible, recommended by Guttman (1999) and Vicente-Serrano, Beguria, and Looez-Mareno (2010) by using the software, EasyFit. Candidate distributions are tested by applying the goodness of fit using software- EasyFit. This software assigns rank 1 to the probability distribution that best fits to the data and ranks 2 or 3 accordingly. The Kolmogorov-Simonov (KS) test, Anderson-Darling (AD) test and Chi-square test are used for testing of hypothesis of goodness of fit.

The steps, briefly include that, usually $\mathrm{G}(x)$, the function is only defined for $x>0$. For $x<0$, cdf of $x$ is adjusted to $\mathrm{H}(x)=q+(1-q) \mathrm{G}(x)$, where $q$ is the probability of no precipitation or zero. $q$ is empirically measured as the ratio of number of events of no rain to the total number of events in a given time-series. However, this study has no problem of zero precipitation. Thus, $\mathrm{H}(x)$ is equivalent to $\mathrm{G}(x)$. The cumulative probability $\mathrm{H}(x)$, is then transformed to the standard normal distribution, $\Phi$ $(z)$ with zero mean and unit variance of a new random variable, $Z$ (Edwards $\&$ McKee, 1997). This $Z$ is thus a SPI. However, this SPI obtained by above simple approach is easy but not practical for large

Copyright \& License @ Central Department of Statistics, TU, 201879 
number of data points (Sigdel \& Ikeda, 2010). For this study, the approximation provided by Abramowitz and Stegun (1965) was used and given below.

$$
\begin{aligned}
& \mathrm{SPI}=z=-\left(t-\frac{c_{0}+c_{1} t+c_{2} t^{2}}{1+d_{1} t+d_{2} t^{2}+d_{3} t^{3}}\right) \text { for } 0<H(x)<0.5 \text { where } t=\sqrt{\operatorname{Ln}\left(\frac{1}{(H(x))^{2}}\right)} \text { for } 0<H(x)<0.5 \\
& S P I=z=+\left(t-\frac{c_{0}+c_{1} t+c_{2} t^{2}}{1+d_{1} t+d_{2} t^{2}+d_{3} t^{3}}\right) \text { for } 0.5<H(x)<1.0 \text { where } \\
& t=\sqrt{\operatorname{Ln}\left(\frac{1}{1-(H(x))^{2}}\right)} \text { for } 0.5<H(x)<1.0 \\
& c_{0}=2.515517, c_{1}=0.802853, c_{2}=0.010328, d_{1}=1.432788, d_{2}=0.189269, d_{3}=0.001308
\end{aligned}
$$

The derived SPI was considered as a normally distributed random variable. It was interpreted as a number of standard deviations that the observed value would deviate from the long-term mean. For the interpretation of the SPI, McKee et al. (1993) presented the following drought categories from SPI.

Table 2. Drought/wet categories for SPI

\begin{tabular}{cc}
\hline SPI & Drought Category \\
\hline 2 or above & Extreme wet \\
$1.50-1.99$ & Very wet \\
$1.00-1.49$ & Moderately wet \\
-0.99 to 0.99 & Near normal \\
-1.00 to -1.49 & Moderate drought \\
-1.5 to -1.99 & Severe drought \\
-2.00 or less & Extreme drought \\
\hline
\end{tabular}

Source: McKee et al. (1993)

\section{RESULTS}

Results are described as follows.

\section{Probability distribution fitting}

Before computing SPI-3, SPI-4 and SPI-12, it is required to test whether all three timeseries, e.g., 3-months (December-February), 4-months (June-September) and 12-months (JanuaryDecember) time-series of the precipitation amounts, have a goodness of fit to a theoretical distribution like Gamma distribution with two parameters or other. This test was applied for baseline and future periods separately. These are most commonly used distributions, for example, Gamma, 
Lognormal, Logistic, Weibul and GEV of which the best one may be considered for selection. The criterion to select each distribution is to use the outputs of the software- EasyFit (Easy-Fit, 2013). The Table 3 and Table 4 present the results of goodness of fit test using the EasyFit software.

Table 3. Fitting of first ranked probability distribution for precipitation amount at 3 time-scales for two periods

\begin{tabular}{rcccc}
\hline \multirow{2}{*}{ Period } & Seasonal & Kolmogorov- & Anderson-Darling & Chi-squared \\
& Rainfall & Smirnov Test & Test & Test \\
\cline { 3 - 5 } & & Distribution & Distribution & Distribution \\
\hline Baseline: Winter & DJF rainfall & GEV & GEV & Lognormal \\
Future: Winter & DJF rainfall & Lognormal & GEV & GEV \\
Baseline: Summer & JJAS rainfall & GEV & GEV & Weibull(3P) \\
Future: Summer & JJAS rainfall & GEV & GEV & Lognormal \\
Baseline: Annual & JD rainfall & GEV & GEV & Weibull(3P) \\
Future: Annual & JD rainfall & GEV & GEV & GEV \\
\hline
\end{tabular}

At least two goodness of fit tests have demonstrated that GEV is the most fitted distribution to all the periods for the rainfall (Table 3). The parameters of GEV distribution were estimated by the L-moments method (Hosking, 1990) using EasyFit. The estimates are presented in Table 4.

Table 4. Estimates of parameters of GEV distribution using method of L-moments

\begin{tabular}{ccccc}
\hline \multirow{2}{*}{ Period } & Seasonal & \multicolumn{3}{c}{ Parameters of GEV Distribution } \\
\cline { 3 - 5 } & Rainfall & $\mu$ & $\sigma$ & $\Xi$ \\
\hline Baseline: Winter & DJF rainfall & 29.56 & 16.476 & 0.24287 \\
Future: Winter & DJF rainfall & 15.71 & 24.889 & 0.28563 \\
Baseline: Summer & JJAS rainfall & 1296.8 & 214.9 & -0.21457 \\
Future: Summer & JJAS rainfall & 1347.4 & 228.68 & 0.07752 \\
Baseline: Annual & JD rainfall & 1600.2 & 185.45 & 0.00661 \\
Future: Annual & JD rainfall & 1666.4 & 241.15 & 0.07152
\end{tabular}

Using the GEV probability distribution, the SPIs for 3-, 4- and 12- months were calculated for both periods. The assessment of these SPIs is discussed in the following section.

\section{Copyright \& License @ Central Department of Statistics, TU, 201881}




\section{SPI-3, SPI-4 and SPI-12 for base period and future period}

A 3-month SPI (for winter in February), a 4-month SPI (for summer in September) and a 12month SPI (in December) were computed for two periods 1971-2000 (baseline) and 2030-2060 (future: Mid-Century Period), respectively. These SPIs were constructed for the drought analysis as they are applicable for agricultural and hydrological aspects (Sigdel et al., 2010). Further, Sigdel (2010) has stated that the drought evolution over Nepal mainly concerns with the deficit of rainfall in relation to summer monsoon (Southeasterly) and wintertime (Westerly) circulations. Bar diagrams of SPI-3, SPI-4 and SPI-12 were constructed against year for both periods in the same X-Y plane ((Fig. 2, Fig. 3 \& Fig. 4).

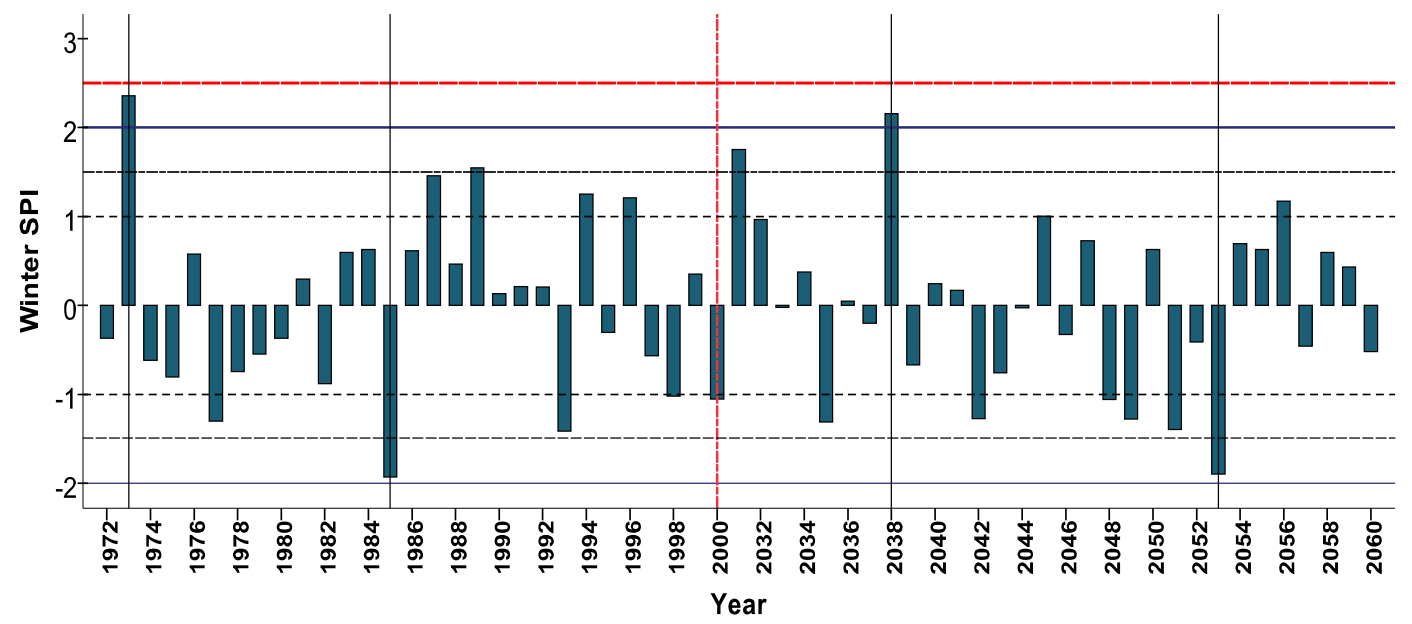

Fig. 2. Year-wise distribution of 3-month average SPI in February.

The behavior of drought and wet events has revealed similarity in their occurrence during the baseline period. Thereafter, no such events are evident. It may indicate tendency of dryness up to moderately drought situation during this period. Moderate winter wets seemed to occur in 1987, 1994 and 1996. It may reappear asvery wet in 2031 but moderately wet in 2032, 2045 and 2056. The baseline period seemed to have less number of wet events compared to those expected in future. When the drought events are observed, severe drought had occurred in 1985 in baseline but it seems that it may not reappear in future. Further, moderate winter drought occurred in 1977, 1993, 1998 and 2000. It is expected to reoccur in 2035, 2042, 2048, 2049, 2051 and 2053. In future, it is expected that there will be more frequent drought events compared to the baseline.

Figure 3 has displayed the bar diagrams of SPI-4 for monsoon season in different years for both baseline and future. Following the same criteria applied above (Table 1), a little extreme or very wet event happened in 1972 and 1991, respectively in baseline. But this event may reappear as a very wet 
event in 2036, 2058, 2059 and 2060 in future. Furthermore, this indicates that very wet event may happen more frequently in future than those had happened during baseline. But the tendency of moderate wet events seems equally distributed in both periods. The future events are likely have some different pattern. The tendency of being wet event may have more likelihood than that being a drought event in future. But it is also clear from the Figure that there were one extreme drought events in 1993 and one severe drought in 1998. They are likely to reappear in 2030, 2046 and 2053. More drought events seemed likely to happen in future. The scenarios of some hydrologic events behaves like some more wet events in some years and some more dry events some other years in future. However, the wet event may happen little more than the drought event in future. Thus, these altering hydrologic happenings may happen due to the impact of climate change.

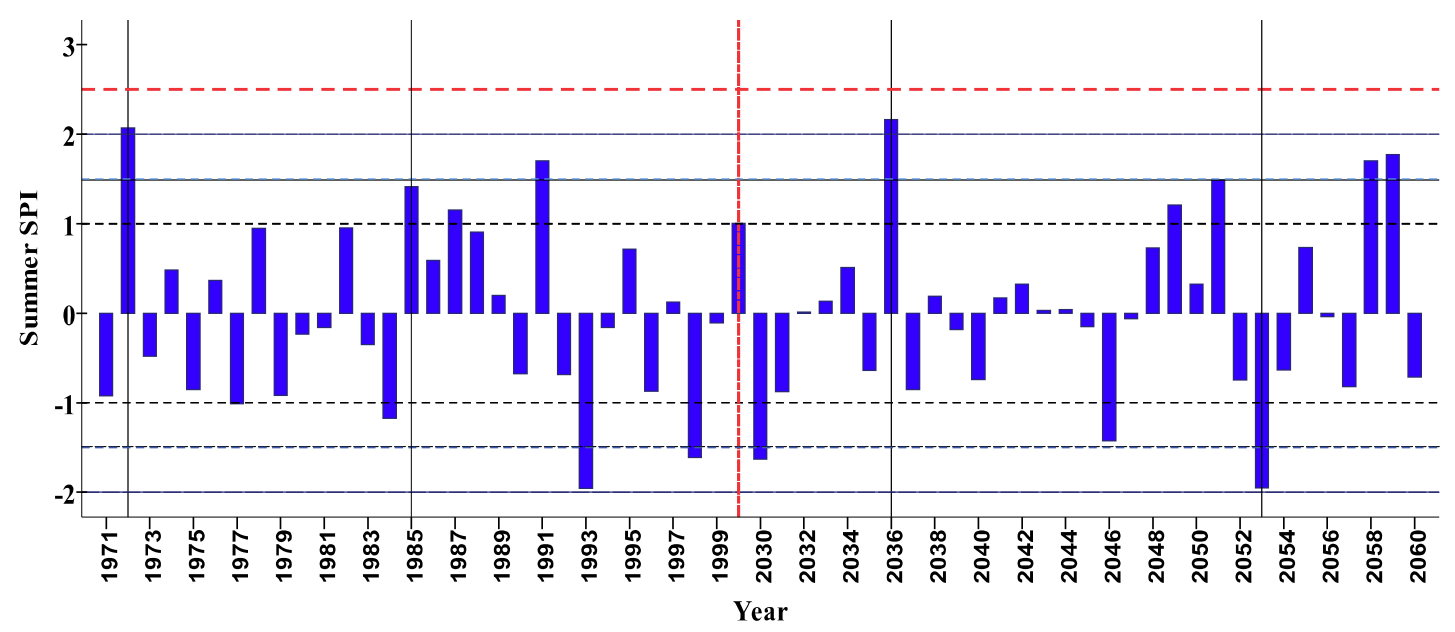

Fig. 3. Year-wise distribution of 4-month average SPI in September.

Hence, the analysis of SPI-4 showed that there may be severe impact in wet events for the monsoon season in future due to climate change despite few drought events. Figure 4 has displayed the bar-diagrams of SPI-12 calculated from 12 month precipitation amount in December in different years for both baseline and future. The patterns of the drought events seemed homogenous in both baseline and future periods. Nevertheless, a number of moderate or more drought events seem less likely than a number of moderate or wet events in future. Following the same criteria applied above (Table 3), one extreme wet event occurred in 1972 but such an event may not happen in future. Very wet or moderate wet events occurred in 1991 and 2000 in baseline. It is likely that such events occur more frequent in future years 2036, 2058 and 2059 depicting very wet events.

Moderate drought events seemed more likely to occur in future than those happened in baseline. However, the extreme drought occurred in 1993 and severe drought in 1975. It may reappear as Copyright \& License @ Central Department of Statistics, TU, 201883 
severe drought in 2046. Similarly, there was moderate drought in 1992. It is likely to reoccur in 2030, 2031, 2035, 2040 and 2053. These results are consistent with the results of SPI-4 in drought analysis. One peculiarity in this analysis is that there seem more moderate drought events than moderate wet events in future. Compared to the baseline results, the drought events may be more frequent in future. This means that there may be more drought events in long-term in future. Hence, there may be possible impact of climate change on the hydrology of the Bagmati River Basin considering drought event in the long-run in future.

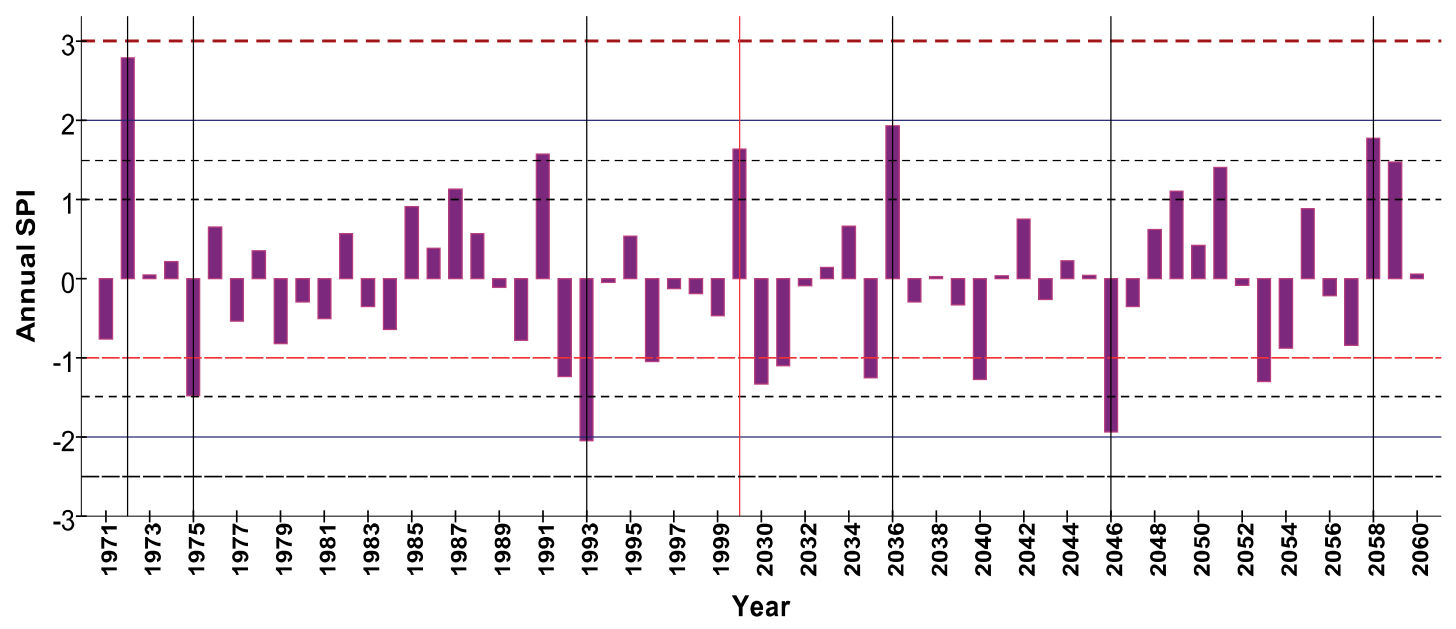

Fig. 4. Year-wise distribution of 12 month average SPI in December.

\section{DISCUSSION}

Analyses of SPI-3, SPI-4 and SPI-12 belonging to RCM (PRECIS) model with nested GCM, ECHAM05-MPI and SRES A1B, scenario have shown varying conditions of wet and drought events at the study region. Accordingly, winter drought is likely to be more frequent in future. The degree of dryness seems more likely in this period. If such events persist in future, naturally, it will create the problem of drinking water, requirement of load-shedding or irrigation especially in the Bagmati River Basin, Nepal. The winter drought analysis displayed more drought events. A number of years concerning moderate drought seems more likely in future. Year 1985 was severe drought year. But tendency of years being droughts seems more likely in future compared to baseline.

The summer drought indicates that very wet events may happen more frequently in future than those have happened during baseline. The patterns of the drought events seem homogenous in both periods. Nevertheless, a number of extreme or severe drought events are less likely than a number of moderate or very wet events in future. Hence, the analysis of SPI-4 shows that there may be severe impact in wet events in future due to climate change despite few drought events. If such events really 
persist, there may be no doubt that some natural hazards like flash floods and landslide may occur in future. Consequently, it is most likely to bring loss of life or properties, or socio-economic decline in the livelihood of people in the study area. The annual drought analysis shows that there may be more moderate drought events than moderate wet events in future. Compared to the baseline results, the drought events may be more frequent in future. This means that there may be more drought events in long-term in future. This indicates that there may be hydrological drought as the longer-term precipitation anomaly at the Basin. If this event really happens, there could be some effects of the climate change in the reservoir electricity project like Kulekahni hydropower project (Dhakal, 2011), Pharping Hydro Power Project and the Bagmati irrigation project or upcoming new projects.

With application of SPI, it is thus concluded that there may be some likelihood of serious drought or wetness in the Bagmati River Basin in future with respect to ECHAM05, GCM and A1B scenario. The study also shows that drought episodes of moderate or severe type may occur in future as well. Other researchers have also reported the drought events which almost matched or are consistent with the results of this study. Bhuyian (2004) used the SPI to assess the precipitation deficit and meteorological drought computed from 35 rain-gauge stations. The outcomes of the SPI demonstrated that Aravalli terrain, India in both monsoon and non-monsoon periods follow an erratic rainfall pattern. Further, seasonal drought has appeared in some areas of northern and southwestern Aravalli region, India during years 1984-1985. The drought happened again in the terrain during the monsoon of 1999 and became worst in the season of 2000. Assismakopoulos and Livida (2007) used SPI to detect drought events in Greece on spatial and temporal basis using monthly precipitation data from 23 stations of 51 years. Results indicated that mild and moderate droughts appeared reduced from north to south and from west to east on 3 and 6 months timescale. Furthermore, the frequency of happening of severe and extreme drought is very low over the whole Greek territory on the 12- month running timescale.

Santos, Calvo, and Portelo (2010) assessed the spatio- temporal, variability of drought in Portugal using SPI at 1-, 6- and 12 months scales. The results showed that temporal evolution of droughts was identified at north, central and south regions of Portugal. Gebrehiwot, Veen, and Maathuis (2011) analyzed the spatial and temporal variation of drought in northern highlands of Ethiopia based on the SPI and Vegetation Condition Index (VIP). The results of both indicates demonstrated that the eastern and southern zones of the study area affected by frequent cycle of drought over the lastdecade. The above discussion showed that SPI is more applicable tool as a drought index for all over the world and in all climatic regions for drought assessment. The results of the current/ recent research showed the years 1977, 1985, 1993, 1998, 2000, 2035, 2042, 2048, 2049, 2051 and 2053 having winter moderate drought in the study region. Similarly, the summer extreme

\section{Copyright \& License @ Central Department of Statistics, TU, 201885}


drought was indicated in 1993 and 2053 years. Likewise, the long-term drought was indicated in 1992, 2030, 2031, 2035, 2040, 2053 years for the study region. These results fairly matched with the results of past paper as discussed above. Sigdel and Ikeda (2010) reported some drought events happening in some parts of Nepal. Shrestha et al. (2016) pointed out in his drought risk assessment that summer season of year (2004, 2005, 2006 and 2009) and winter season of year (2006, 2008 and 2009) were the worst widespread droughts in central Nepal.

\section{CONCLUSION}

Winter moderate drought episodes are likely to occur in the years 2035, 2042, 2048, 2049, 2051 and 2053 in the Bagmati River Basin, Nepal on the basis of PRECIS data simulated from ECHAM05-MRI with SRES A1B. Likewise, summer severe drought episode may occur in 2046. This year is also indicated as long-term extreme drought. Moreover, 2030, 2031, 2035, 3040 and 2053 may represent as long-term moderate drought episodes in future. Therefore, winter moderate drought, summer severe drought and a long-term extreme as well as moderate drought may occur during 2030-2060 period in future. In view of likelihood of occurrence of such episodes in future, it is necessary that plans and policies are made accordingly to mitigate the impact of future drought due to climate change and adapt to the adverse consequences of such events in future.

\section{CONFLICT OF INTEREST}

The authors confirm there is no conflict of interest.

\section{ACKNOWLEDGEMENTS}

Authors are grateful to Department of Hydrology and Meteorology, Government of Nepal for providing PRECIS data of baseline (1971-2000) and future (2030-2060).

\section{REFERENCES}

Abramowitz, M., \& Stegun, I. A. (1965). Handbook of Mathematical function. UK: Dover Publications Inc.

Assismakopoulos, V. D., and Livada, I. (2007). Spatial and temporal analysis of Drought in Greece using the Standardized Precipitation Index (SPI). Theor. Appl. Climatol. 89, 143-153.

doi: $10.1007 / \mathrm{s} 00704-005-0227-\mathrm{z}$

Babel, M. S., Bhusal, S. P., Wahid, S. M., \& Agarwal, A. (2013). Climate change and water resources in the Bagmati River Basin, Nepal. Theoretical and Applied Climatology.115, 3-4. doi: $10.1007 / \mathrm{s} 00704-013-0910-4$ 
Bhuyian, C. (2004). Various drought indices for monitoring drought conditions in Arravalli terrain of India (Technical report, Working group VII/5, IIT Kanpur). Retrieved from http://www.cartesia. es/geodoc/isprs2004/comm7/papers/243.pdf

Deka, S., Boraj, M., \& Kakaty, S. C. (2009). Distribution of annual maximum rainfall series of NorthEast India. European Water, 27/28, 3-14.

Dhakal, M. (2011). Climate change impacts on reservoir based hydropower generation in Nepal: A case study of Kulekhani Hydropower Plant.

Retrieved from http://chimalaya.org/2012/03/30/climate-change-impacts-on-reservoir-basedhydropower-generation-in-nepal/

DHM. (2013). Nepal: strengthening capacity for managing climate change and the environmentclimate data digitization and downscaling of climate change projections in Nepal. Consultants' reports. The ADB project 40545-012 in Nepal. Retrieve from https://www.adb.org/projects/40545-012/main

EASY-FIT. (2013). Software for parameter estimation. University of London, UK. Retrieve from departments/math/kschittkowski/easyfit.htm.

Edwards, D. C., \& McKee, T. B. (1997). Characteristics of $20^{\text {th }}$ century drought in the United States at multiple time-scales. Department of Atmospheric Science, Colorado State University, Colorado. Retrieve from https://dspace.library.colostate.edu/handle/10217/170176.

Gebrehiwot, T., Veen, A. V., \& Maathuis, B. (2011). Spatial and temporal assessment of drought in Northern highlands of Ethiopia. International Journal of Applied Earth Observation and Geoinformatics, 13, 209-22. doi.org/10.1016/j. jag.2010.12.002

Guttmann, N. B. (1998). Comparing the Palmer drought index and the standardized precipitation index. J AM Water Res AS, 34, 113-12.

Retrieved from http: //www.wamis.org/agm/pubs/SPI/WMO_1090_EN

Guttman, N. B. (1999). Accepting the Standardized Precipitation Index: A Calculation Algorithm. JAWRA Journal of the American Water Resources Association, 35(2), 311-322. doi:10.1111/j.1752-1688.1999.tb03592.x

Hosking, J.R.M. (1990). L-moments: analysis and estimation of distribution using linear combination of order statistics. J R Stat Soc, Ser B, 52(1), 105-124.

Kafle, H. K. (2014). Spatial and temporal variation of drought in far and mid-western regions of Nepal: Time-series analysis (1982-2012). Nepal J Sci Technol, 15, 65-76.

Lana, X., Serra, C., \& Burgueno A. (2001). Patterns of monthly rainfall shortage and excess in terms of the Standardized Precipitation Index for Catalonia (NE Spain). International Journal of Climatology, 21, 1669-1691.

\section{Copyright \& License @ Central Department of Statistics, TU, 201887}


McKee, T., Doesken, N., \& Kleist, J. (1993). The relationship of drought frequency and duration to time scales. $8^{\text {th }}$ conference on applied climatology. American Meteorological Society, Boston, 179-184.

Mishra, A. K., \& Singh, V. P. (2010). A review of drought concepts. J. Hydrol, 391, 202-216. doi: $10.1016 /$ j.jhydol.2010.07.012

Nepal, S. (2016). Impacts of climate change on the hydrology regime of the Koshi river basin in the Himalayan region. Journal of Hydro-environment Research, 10, 76-89.

Obasi, GPO, (1994). WMO's role in international decade for natural disaster reduction. Bulletin of American Meteorological Society, 75, 1655-1661.

Santos, J. F., Calvo, J. P., \& Portelo, M. M. (2010). Spatial and temporal variability of drought in Portugal. Water Resources Research, 46, W03503, 13.

Shrestha, M. L., Dahal, P., Shrestha, N. S., Panthi, J., Jha, A., Lakhankar, T., and Krakauer, N. Y. (2016). Drought risk assessment in central Nepal: temporal and spatial analysis. Natural Hazards, 80(3), 1913-1932. doi:10.1007/s11069-015-2055-5

Sigdel, M., \& Ikeda, M. (2010). Spatial and temporal analysis of drought in Nepal using standardized precipitation index and its relationship with climate indices. SOHAM-Nepal. Journal of Hydrology and Meteorology, 7(1), 59-74.

Shrestha, M. L. (2000). Inter annual variation of summer monsoon rainfall over Nepal and its relation to Southern Oscillation Index. Meteorol Atmos Phys, 75, 21-28.

Shrestha, A. B., \& Aryal, R. (2010). Climate change in Nepal and its impact on Himalayan glaciers. Reg Environ Change, 11, 65. doi: https://doi.org/10.1007/s10113-010-0174-9

Shrestha, M. L., Dahal, P., Shrestha, N. S., Panthi, J., Jha, A., Lakhankar, T. \& Krakauer N. Y. (2014). Drought risk assessment in central Nepal: temporal and spatial analysis. Natural Hazards, 80(3), 1913-1932.

Vicente-Serrano, S. M., Begueria, S., \& Loòez-Moreno, J. I. (2010). A multi scaler drought index sensitivity to global warming: the standardized Precipitation Evapotranspiration Index. $J$ Clim, 23, 1696-1718.

Wang S. Y., Yoon, J. H., Gillies, R. R., \& Cho, C. (2013). What caused the winter drought in western Nepal during recent years? J Clim, 26, 8241-8256.

Reference to this paper should be made as follows:

Shrestha, R. M., Sthapit, A. B., \& Shrestha, S. L. (2018). A probabilistic approach for assessment of future drought in Bagmati River Basin, Nepal. Nep. J. Stat., 2, 75-88. 